\title{
Improving the Efficiency of a Nuclear Power Plant Using A Thermoelectric Cogeneration System
}

\author{
Rauf Terzi ${ }^{a}$, and Erol Kurt ${ }^{b}$ \\ ${ }^{a}$ Turkish Atomic Energy Authority, Çankaya, Ankara Turkey \\ ${ }^{b}$ Department of Electrical and Electronics Engineering, Faculty of Technology, University of Gazi, Teknikokullar, Ankara Turkey
}

\begin{abstract}
The efficiencies of nuclear power plants are rather poor having the ratio \%30 by using the conventional energy/exergy tools. According to that information, large amount of energy is wasted during condensation and thrown out to the environment. Thermoelectric generator (TEG) system has a potential to be used as a heat exchanging technology to produce power with a relatively low efficiency (about 5\%) and it can transform the temperature difference into electricity and generate clean electrical energy. In the present study, we offer a novel system to recover the waste heat from a VVER-1000 nuclear power plant. The heat transfer of the TEG is analyzed numerically with respect to the various temperature ranges and constant mass flow rate of the exhaust steam entering the system. In the analyses, different hot temperature ranges $\left(35^{\circ} \mathrm{C}, 45^{\circ} \mathrm{C}\right.$ and $\left.55^{\circ} \mathrm{C}\right)$ and a constant cold temperature (i.e. $18^{\circ} \mathrm{C}$ ) are used for a HZ-20 thermoelectric module and it has been proven that the designed TEG can produce the maximum output power of $76.956 \mathrm{MW}$ for a temperature difference $\Delta \mathrm{T}=37$ and the conversion efficiency of $3.854 \%$ sits. The TEG is designed for the condenser of a $1000 \mathrm{MW}$ nuclear power plant. It's shown that about $2.0 \%$ increasing in the power plant efficiency is expected by using the selected thermoelectric generator in the condensation cycle.
\end{abstract}

Keywords: Thermoelectric, cogeneration, nuclear power plant, efficiency.

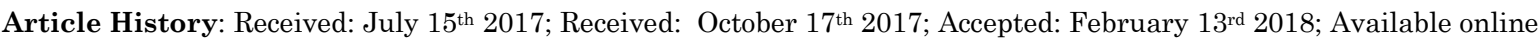

How to Cite This Article: Terzi, R. and Kurt, E. (2018), Improving the efficiency of a nuclear power plant using a thermoelectric cogeneration system, Int. Journal of Renewable Energy Development, 7(1), 77-84.

https://doi.org/10.14710/ijred.7.1.77-84

\section{Introduction}

In a previous paper (Terzi et al 2016), we have studied the energy and exergy analysis of a nuclear power plant, (NPP), namely VVER 1000. It has been found that the exergy becomes low for such plants, since the high temperature inside the reactor core should be decreased for the safe usage of the fuel. Even the successive paths for condensers and pumps affect the exergy in a negative way in such plants. In order to decrease the energy loss and to increase the efficiency of such systems there exist some cogeneration attempts in the literature. Based on previous study (Terzi et al 2016), the greatest energy loss occurs in condensers. However its retrieval is difficult since the condensation of vapor takes place at low temperature and pressure.

Modern nuclear power plants produce heat from nuclear reaction to create electrical power. Water and oil are used to transport heat energy from the power plant to the turbine (Fig.1). During transport, much of the heat energy is wasted. The efficiency of these plants is at most $34 \%$ and obviously the rest of the energy is unused or lost.

A solution to regain the wasted heat is to place thermoelectric devices, or thermoelectric, in-line with the path of the fluid. The technology behind thermoelectric devices is the temperature differences between the two plates. An electrical insulator is placed between the two plates. The thermoelectric generators use heat exchanging technology to produce the power; in the order of watts. The temperature of the fluids are relatively low, under $300^{\circ} \mathrm{C}$ (Gabbar et al 2017). Capturing the excess heat from that area with the thermoelectric generators provides auxiliary energy production (Gabbar et al 2017). Waste heat recovery is considered to be one of the best solutions because it can improve energy efficiency by converting heat exhausted from plants to electric power.

Thermoelectric power generation is adequate for utilizing such low-grade heat and improving the total efficiency of power plants. Thermoelectric generation is a direct and clean heat-to-electricity conversion, and

\footnotetext{
*Corresponding authors: rauftr@gmail.com
} 
can be operated even if the temperature difference between the heat sources is small (Kyono et al 2003).

TEG provides direct energy conversion from the thermal energy because of the temperature gradient from one side of the device to the other side. Those devices operate based on Seebeck effect (Hendricks and Choate, 2006).

Thermoelectric generators (TEG) has an important place in the use of renewable energy sources (Riffat and Ma, 2003). Many developed countries have been the subject of new researches in technological innovations with regard to the use of TEG (Xi et al 2007). Mainly, TEGs are used in the operations having waste heat temperature difference to obtain the electrical power. Even as a small power requirement battery, it can be used widely (Tsai and Lin, 2009). TE power generation has an advantage of being substantially maintenance free, silent in operation and involving no moving or liquid complex parts. However, the efficiency of the conversion has not managed to exceed $5 \%$ for the temperature ranges of practical interest (Gou et al 2010).

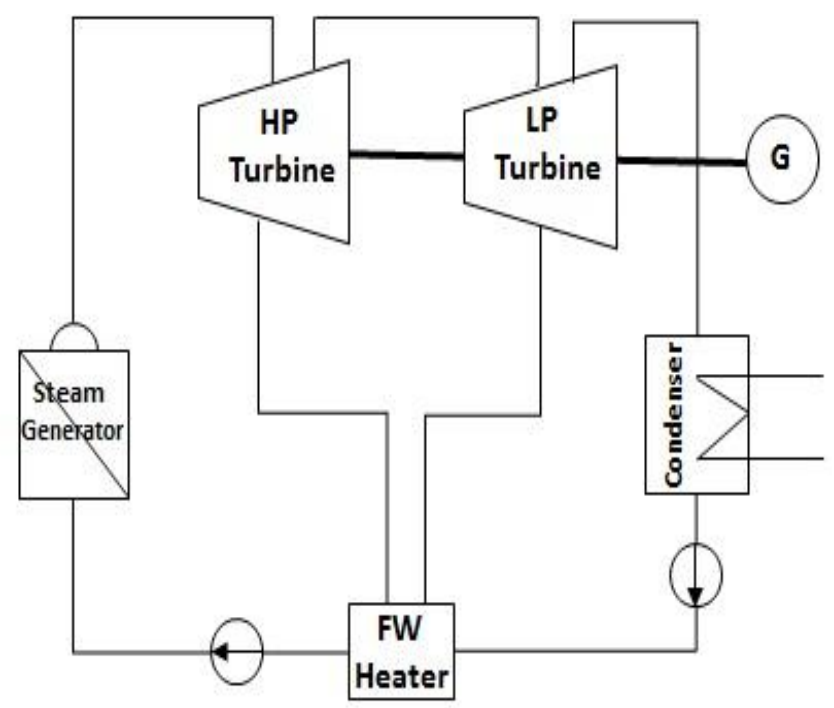

Fig. 1 The internal nuclear power plant cycle.

The purpose of this work is to propose the utilization of unused energy in condensers by means of thermoelectric conversion and to calculate a theoretical amount of energy retrieval in condenser. An evaluation of a prototype thermoelectric cogeneration unit is considered in order to get usable electrical energy from a VVER type NPP. The reactor with $1000 \mathrm{MW}$ is handled in the calculations and the TEG operates with the exhaust steam and cooling water from the recycling of discarded heat evaluation of applications. Integration of TEGs with a condenser makes it possible to increase efficiency (heat exchanger becomes a cogeneration unit) and produce electricity for certain amount.
This paper is organised into five sections organised as follow. Section 2 gives a brief study on the cogeneration procedures of the NPPs. Section 3 explains briefly the TEG devices. The main findings and discussion are made in the next section. Finally, the paper is completed by the concluding remarks.

\section{Cogeneration Opportunities for Recovering Waste Heat of Nuclear Power Plants}

The term "cogeneration" is known as the combined heat and power (CHP) and it underlines an efficient, clean and reliable methodology for the generation of power and thermal energy from a single fuel source. In general, cogeneration plants recover a certain proportion of the waste heat, which is discarded from a conventional power generation. The recovered waste heat can be effectively used in other energy applications. Since the present NPPs have low thermal efficiencies within a range of $30 \%$ to $40 \%$ compared to other steam cycle energy conversion systems, one can use cogeneration procedures to increase the efficiency of those plants. According to Khamis and his colleagues (Khamis et al 2013), such efficiencies could be increased up to $80 \%$ by introducing the cogeneration with other applications such as seawater desalination, hydrogen production, district heating or cooling, or any industrial application. The usage of nuclear energy for the cogeneration can provide a benefit of using a nuclear fuel in a much effective way and ecologically friendly. According to one of our earlier studies (Terzi et al 2016), Energy and exergy analyses of VVER type NPP have proven that $30.316 \%$ efficiency exists in the plant. It means that a huge amount of heat is lost during the operation and at least some part of the waste energy may be retrieved by suitable and secure cogeneration method. It should be also considered that the integration of cogeneration sub-system and NPP may be affected by the performance parameters of the NPP.

\section{Concept of Thermoelectric Generation in Condenser}

The nuclear power plant condenser shown in Fig. 2 consists of shell and tube heat exchanger in which the exhaust wet steam of the low pressure turbine is entered the shell and cooling water is circulated through the tubes. The steam heat is absorbed by the cooling water which condenses the wet steam in to the water with about $35^{\circ} \mathrm{C}, 45^{\circ} \mathrm{C}$ and $55^{\circ} \mathrm{C}$ temperature. The temperature of the cooling water is kept in about $18^{\circ} \mathrm{C}$ by circulating it in a sea water. Theoretical design of NPP is used with an average temperature difference between condensed water and cooling water (sea water) under the conditions: 17, 27 and 37 respectively. 


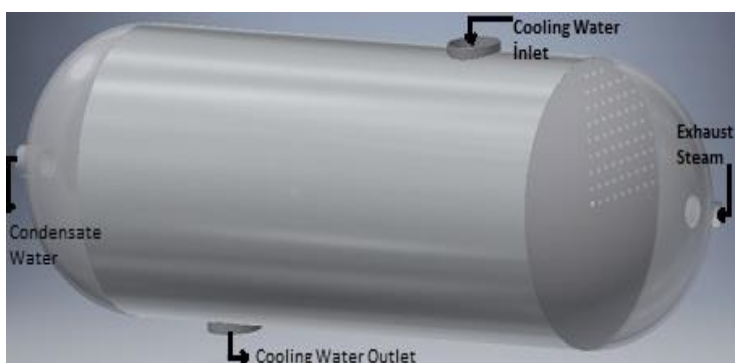

(a)

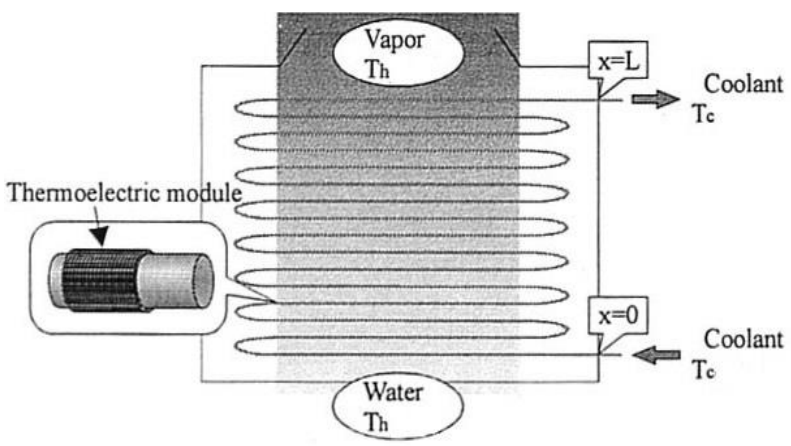

(b)

Fig. 2 (a) The schematic diagram of condenser, (b) Model of condenser for calculation.

An NPP exhausts steam from the low pressure turbine which is condensed with the cooling water (sea water or river water) in the unit of condenser, then the condensated water is turned into the feed water. During that closed loop the condensated water can be send to a steam generator by feeding water pumps and in this way a circulation can be realized. Almost $50-60 \%$ of the input energy is lost during the condensation process where the energy of the steam is rejected to the water.

In the present study, the waste heat to produce the electricity is proposed by utilizing the temperature difference between the inlet temperature of exhaust steam and the inlet temperature of sea water in the condenser unit in such a procedure.

The theoretical proposed TEG heat exchanger unit with two-fluid, counter/parallel flow type is schematized as shown Fig. 3(a). In this study, a TEG unit is placed at the exit of an condenser. The TEG unit consists of a shell and tube heat exchanger whose tubes are covered with thermoelectric materials. The TEG unit, the hot fluid (waste heat) flows the tubes, namely, using temperature difference between exhaust steam and cooling water to generate electricity by HZ-20 TE modules covered on the tubes (see Fig.3(c)). The largest portion of waste heat energy lies within the hundreds of steam lines transporting low pressure steam from the turbine to condenser.

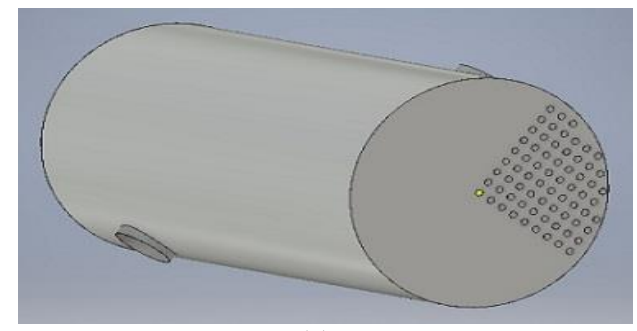

(a)

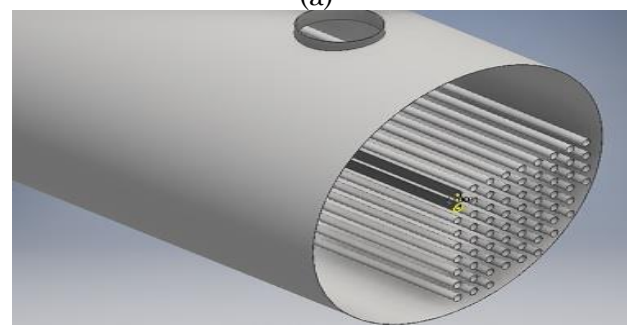

(b)

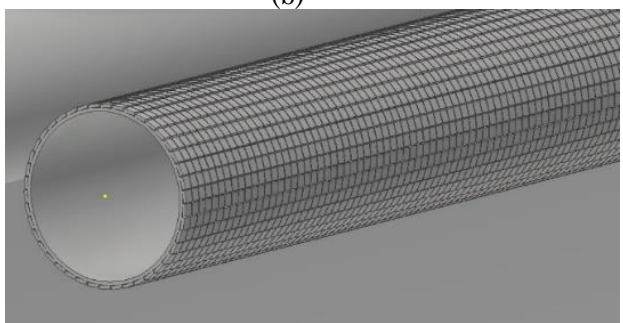

(c)

Fig. 3 (a) The inside view of the revised TEG prototype of condenser, (b) The schematic representation of arrangement of TE modules inside of the condenser, (c) The covered with thermoelectric modules design for the tube.

For the purpose of heat energy recovery a model based on thermoelectric power generation system prototype was developed shown in Fig. 3. In that case, the voltage and electric power of HZ-20 thermoelectric modules are performed according to the module performance calculator. HZ-20 module can be used because it has interesting technical features in terms of power output and conversion efficiency.

\section{Thermoelectric module, HZ-20}

$\mathrm{Hi}-\mathrm{Z}$ technology, Inc is one of the thermoelectric module's manufacturers in the world. Hi-Z modules are based on bismuth telluride semiconductor alloys and are most efficient in temperature ranges from -20 ${ }^{\circ} \mathrm{C}$ - to $300^{\circ} \mathrm{C}$. The HZ-20 module consists of 71 thermocouples arranged electrically in series and thermally in parallel. The thermocouples consist of "Hot Pressed", Bismuth Telluride based semiconductors to give the highest efficiency at most waste heat temperatures as well as high strength capable of enduring rugged applications [http://hiz.com/wp-content/uploads/2017/05/Data-Sheet-HZ20.pdf]. The bismuth-telluride offered the best performance and operability in spite of its lower maximum operating temperature. 


\section{Thermoelectric Energy Generator}

A thermoelectric generator (TEG) functions to convert thermal energy or a temperature difference across the thermoelectric device directly into useful electricity. A schematic diagram of a simple thermoelectric generator operating on Seebeck effect is shown in Fig. 4 (Ismail and Ahmed, 2009). A basic TEG includes a thermocouple consisting of an N-type material with excess electrons and a P-type one with deficit of electrons (Bianchini et al 2014). They are connected electrically in series and thermally in parallel in the TEG structures. The TE modules can be manufactured on ceramic plates to provide an electrical insulation for the $\mathrm{P}$-type and $\mathrm{N}$-type Bismuth Telluride (BiTe) thermoelements. In that structure, the output voltage for such a junction can be explained by a certain temperature difference between hot and cold sides and it is called as Seebeck coefficient and denoted by $a$. That coefficient changes in the range $0-50 \mu \mathrm{V} / \mathrm{K}$ for metals and $300 \mu \mathrm{V} / \mathrm{K}$ for semiconductors (Rowe and Min, 1996).

Heat is transferred at a rate of $\mathrm{Q}_{\mathrm{h}}$ from high temperature heat source maintained at hot junction temperature $\mathrm{T}_{\mathrm{h}}$. Heat is rejected at a rate of $\mathrm{Q}_{\mathrm{c}}$ to a low temperature heat sink maintained at cold junction temperature $\mathrm{T}_{\mathrm{c}}$. The heat supplied at the hot junction causes electric current to flow in the circuit and electrical power is produced.
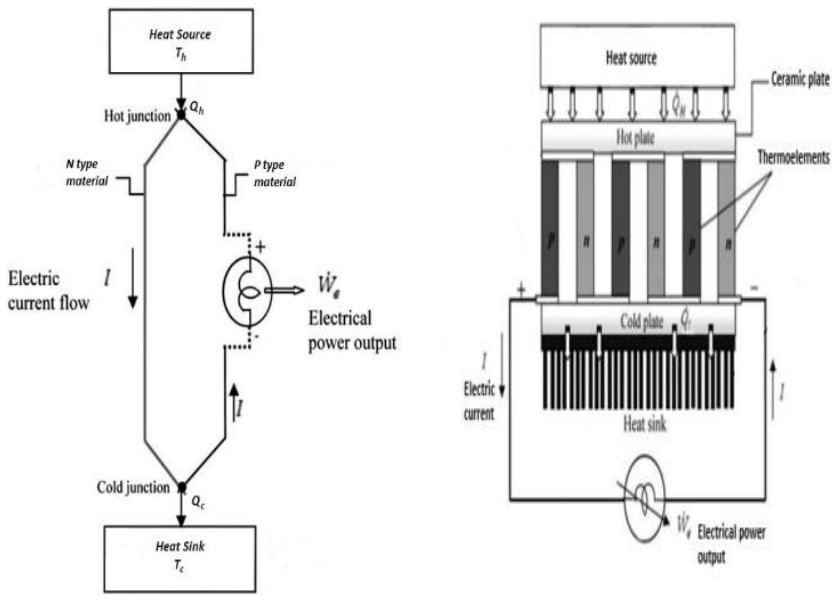

Fig. 4. (a) Schematic diagram of a simple thermoelectric generator and (b) Mechanism of thermoelectric power generation.

The figure-of-merit is often expressed in its dimensionless form, ZT where $\mathrm{T}$ is absolute temperature ZT is calculated as follows (Rowe, 2006):

$$
Z T=\alpha^{2} \sigma T / K
$$

According to (1) and also the units of a and $\kappa, \mathrm{ZT}$ changes with temperature variation. In fact, the amount of the ZT, in the desired temperature, is one of the most important parameters to choose a TE material. Bismuth telluride (Bi2Te3) has the highest value for low to room temperature applications, making it the best candidate for a low grade waste heat recovery

(http://www.thermoelectrics.caltech.edu/thermoelectri cs/index.html).

Where a $(\mathrm{V} / \mathrm{K})$ is the material seebeck coefficient, $\sigma$ $(\mathrm{S} / \mathrm{m})$ electrical conductivity and $\kappa$ (W.m-1.K-1) is thermal conductivity. Electrical resistivity of the material $\rho(\Omega . m)$ can be obtained from electrical conductivity:

$$
\rho=1 / \sigma
$$

The temperature difference between the hot and cold side of the TE generator is :

$$
\Delta T=T_{h}-T_{c}
$$

Where, $\mathrm{T}_{\mathrm{h}}$ is the hot side and $\mathrm{T}_{\mathrm{c}}$ is the cold side temperature in Kelvin.

Measured voltage in such system can be written as,

$$
V=\alpha \Delta T
$$

The measured voltage is given by $\mathrm{V}$ in Volts and the differences of the material coefficients are denoted by $\alpha(=\alpha 2-\alpha 1)$ in $V /{ }^{\circ} \mathrm{C}$. The value of $\alpha$ depends on the characteristics of the material forming the circuit, for instance, $\boldsymbol{a}$ is $40 \mathrm{\mu V} /{ }^{\circ} \mathrm{C}$ for a Copper - Constantan thermocouple. In the case of semiconductors, $\alpha$ is greater with $100 \mathrm{\mu V} /{ }^{\circ} \mathrm{C}$ and therefore, those materials are called as thermoelectric semiconductors.

The output current is calculated as given equation or the output current and internal resistance $(R)$ of HZ-20 thermoelectric modules are performed according to the module performance calculator, which can be obtained by Ref. [10].

$$
I=V /\left(R_{L}+R\right)
$$

The electrical power output is :

$$
P=I^{2} R_{L}
$$

The input heat to the TE generator is calculated as follows:

$$
Q_{h}=\propto I T_{h}-0,5 R I^{2}+K \Delta T
$$

Where thermal conductance of the couple $(\mathrm{K})$ is:

$$
K=\mathrm{\kappa} A / l
$$

Similarly, the first law of thermodynamics can be applied to the system of TEG and power supply to obtain the power consumed by the TEG as shown in Fig.5. 


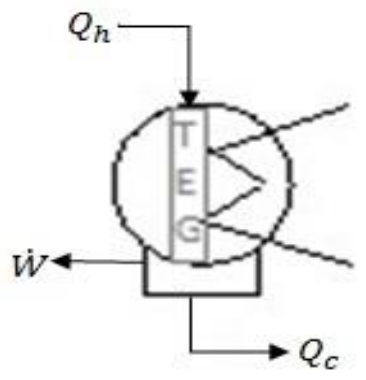

Fig. 5. Energy balance for a TEG

$$
\dot{W}=P=Q_{h}-Q_{c}
$$

The efficiency of the thermoelectric generators can be obtained as,

$\eta=\frac{Q_{h}-Q_{c}}{Q_{h}}=\frac{P}{Q_{h}}$

\section{Thermoelectric Condenser Design}

The reactor with $1000 \mathrm{MW}$ is handled in the calculations and the TEG operates with the exhaust steam and cooling water from the recycling of discarded heat evaluation of applications. The efficiency of nuclear power plant is typically around $30.316 \%$ (Terzi et al 2016). The input energy $\left(\mathrm{P}_{\mathrm{f}}\right)$ is: $\mathrm{P}_{\mathrm{f}}=1000 / 0.30316=3298.588 \mathrm{MW}$.

About $60 \%$ of the input energy is wasted during the condensation process. So the input energy of the condenser $(\mathrm{Pc})$ is calculated as previous study (Terzi et al 2016]: $\mathrm{Pc}=1996.8 \mathrm{MW}$ as seen in Fig. 6 . $6,72 \times 6,72 \times 0,57 \mathrm{~cm}$ bismuth telluride (Bi2Te3) HZ-20 TE module is selected for the designing. Its seebeck coefficient is performed according to the module performance calculator: $0.024 \mathrm{~V} / \mathrm{K}$. It has high electrical conductivity of $40.35 \mathrm{~S} / \mathrm{m}$ and very low thermal conductivity of $0.154 \mathrm{~W} \cdot \mathrm{m}^{-1} \cdot \mathrm{K}^{-1}$.

In order to make the calculations by using the formulas above, we have used various temperature differences as will be pointed out later. From the electrical point of view, each TEG module has an internal impedance of $0.15 \Omega$. Thus, the maximal output power can be gained for that value of load (i.e. $R_{L}$ ) from one module. In that case, that is also important how the connections of TEG modules have been implemented. For that case study, we have used a series connection of all thermoelements. In that case the total internal impedance is expected as $\mathrm{R}=0.234$ $\mathrm{k} \Omega$ for the temperature difference $\Delta T=37$. In all calculations, that load value has been utilized.

The temperature of the wet steam entered the condenser which is also the temperature of the hot side of the TEG, is supposed: $\mathrm{T}_{\mathrm{h}}=308,318$ and $328 \mathrm{~K}$. The temperature of the cold side of the TEG is: $\mathrm{T}_{\mathrm{c}}=$ $291 \mathrm{~K}$
Table 1.

The results of HZ-20 thermoelectric module at $\Delta \mathrm{T}=17, \Delta \mathrm{T}=27$ and $\Delta \mathrm{T}=37$

\begin{tabular}{llll}
\multicolumn{1}{c}{$\Delta \mathrm{T}$} & 17 & 27 & 37 \\
\hline $\mathrm{V}($ volts $)$ & 0.410 & 0.669 & 0.929 \\
$\mathrm{I}(\mathrm{amps})$ & 1.112 & 1.736 & 2.339 \\
$\mathrm{R}(\mathrm{ohm})$ & 0.215 & 0.227 & 0.234 \\
$\mathrm{R}_{\mathrm{L}}(\mathrm{ohm})$ & 0.154 & 0.159 & 0.163 \\
$\mathrm{~K}\left(\mathrm{Wm}^{-1} \mathrm{~K}^{-1}\right)$ & 0.159 & 0.140 & 0.122 \\
\hline
\end{tabular}

Theoretical calculations are conducted for a range of operation conditions as follows: the hot fluid inlet temperature is $35^{\circ} \mathrm{C}, 45^{\circ} \mathrm{C}$ and $55^{\circ} \mathrm{C}$ respectively and the cold fluid temperature is constant as $18^{\circ} \mathrm{C}$ (as given Table 1). Hot fluid flowrate is estimated to $18 \mathrm{~kg} / \mathrm{s}$ for a prototype TEG unit. Actually, the total capacity of hot fluid (exhaust steam) flowrate is approximately $900 \mathrm{~kg} / \mathrm{s}$ for a NPP condenser unit.

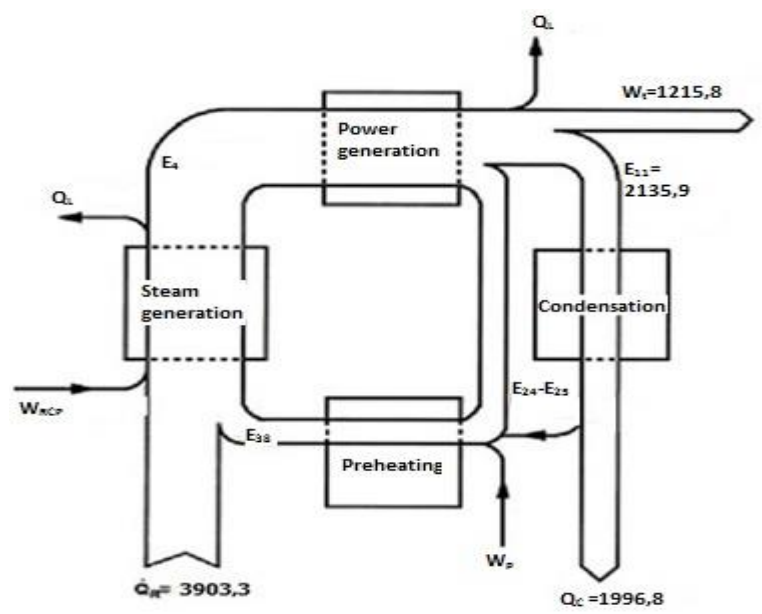

(a)

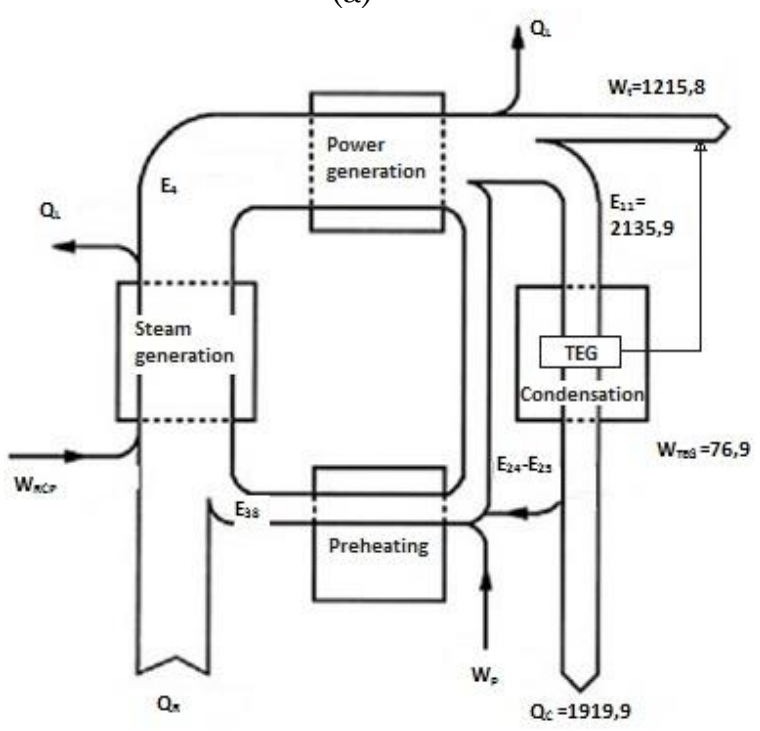

(b)

Fig. 6. (a) The simplified balance diagram for energy (in the units of MW) and (b) The simplified energy balance diagram with the installed prototype TEG unit of NPP. 
Table 2.

The TE module power generation output of as a function of different temperature difference.

\begin{tabular}{llll}
\hline \multicolumn{1}{c}{$\Delta \mathrm{T}$} & 17 & 27 & 37 \\
\hline $\mathrm{P}(\mathrm{W})$ & 0.190 & 0.479 & 0.891 \\
$\mathrm{Q}_{\mathrm{h}}(\mathrm{W})$ & 10.832 & 17.101 & 23.128 \\
$\mathrm{Q}_{\mathrm{c}}(\mathrm{W})$ & 10.641 & 16.622 & 22.237 \\
$\eta(\%)$ & 1.758 & 2.800 & 3.854 \\
\hline
\end{tabular}

The TE module power output was given in Table 2 for the temperature difference $\Delta \mathrm{T}=17,27$ and 37 respectively. In the case of a temperature difference of 27 , the heat $\left(Q_{h}\right)$ is obtained for $17.101 \mathrm{~W}$. The power can be obtained with $0.479 \mathrm{~W}$, a conversion efficiency of $2.800 \%$. Note that the maximal heat $23.128 \mathrm{~W}$ could be obtained for the temperature difference of 37 (for a hot fluid temperature, $\mathrm{T}_{\mathrm{h}}=55^{\circ} \mathrm{C}$ ). The maximal generated power output becomes amount of $0.891 \mathrm{~W}$ can be obtained with $3.854 \%$ efficiency.

According to Table 3, the prototype unit TEG attached to the exhaust part of a condenser unit of VVER NPP can give a power production around 76 MW for the temperature difference $\Delta \mathrm{T}=37$, which is a good value for a co-generation study.

As can be seen from Fig. 7, it was found that by using the TEG unit generator, about 76.956 MW of the wasted heat in the 1000 MW nuclear power plant could be converted to electricity. The thermodynamic efficiency of NPP increased from $30.316 \%$ to $32.649 \%$. It was about $2.0 \%$ increasing in the power plant efficiency by using the selected thermoelectric generator in the condensation cycle.

Table 3.

The results of TEG power generation as a function of different temperature difference.

\begin{tabular}{llll}
\hline \multicolumn{1}{c}{$\Delta \mathrm{T}$} & \multicolumn{1}{c}{17} & \multicolumn{1}{c}{27} & \multicolumn{1}{c}{37} \\
\hline $\mathrm{P}_{\text {Cout }}(\mathrm{MW})$ & 35.105 & 55.918 & 76.956 \\
$\mathrm{~N}_{\mathrm{R}}(\# \mathrm{TE}$ module $)$ & 3298995 & 3364011 & 3460701 \\
$\mathrm{~S}_{\mathrm{R}}(\mathrm{m} 2)$ & 14898 & 15191 & 15628 \\
$\mathrm{P}_{\mathrm{T}}(\mathrm{MW})$ & 1035.105 & 1055.918 & 1076.956 \\
$\eta_{\mathrm{T}}(\%)$ & 31.380 & 32.011 & 32.649 \\
\hline
\end{tabular}

As can be seen from the Fig. 7, the maximum power output and conversion efficiency increase with increasing temperature difference $(\Delta \mathrm{T})$. Furthermore, the peak of maximum power output and conversion efficiency curves occurs where the current is in the range of about 1.0-2.5 (amps).

Fig. 8 shows typical measured output curves with varying the external load resistance at a range of hot fluid inlet temperatures and the fixed cold inlet temperature. It can be seen that the power output increases with increasing the inlet temperature of hot fluid at different load resistance. Therefore, the peak of measured power curves where the load resistance is in the range of about $0.15-0.2 \Omega$.

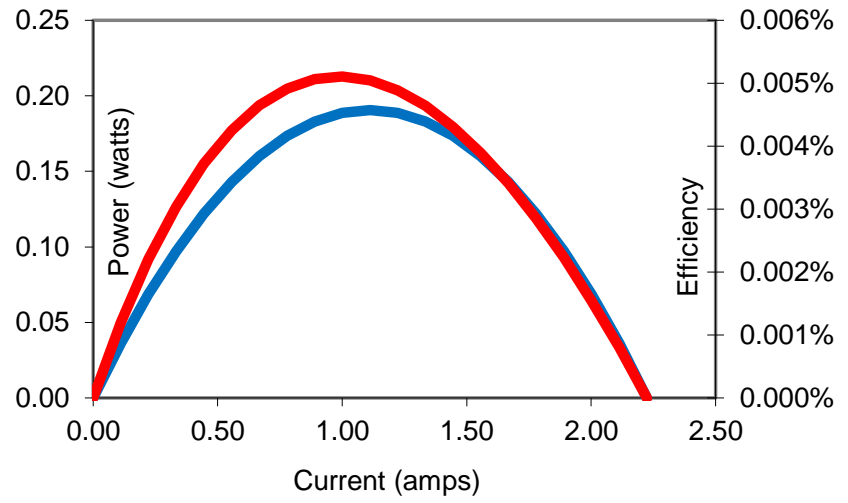

(a)

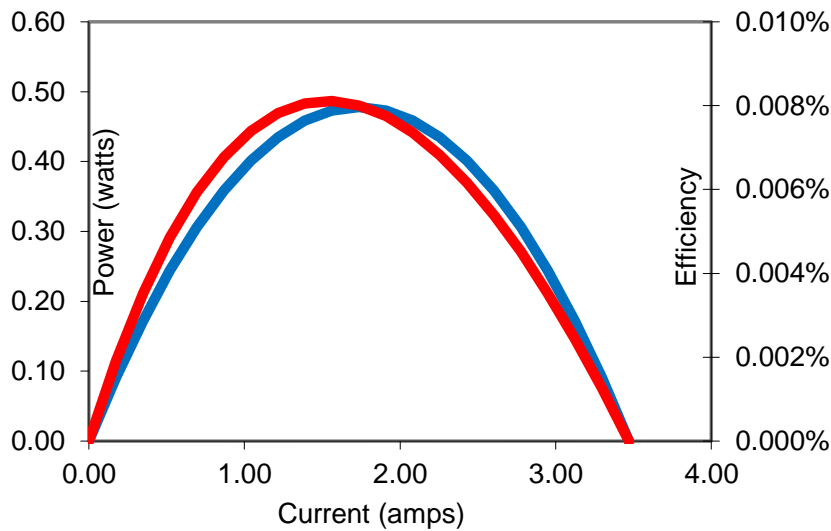

(b)

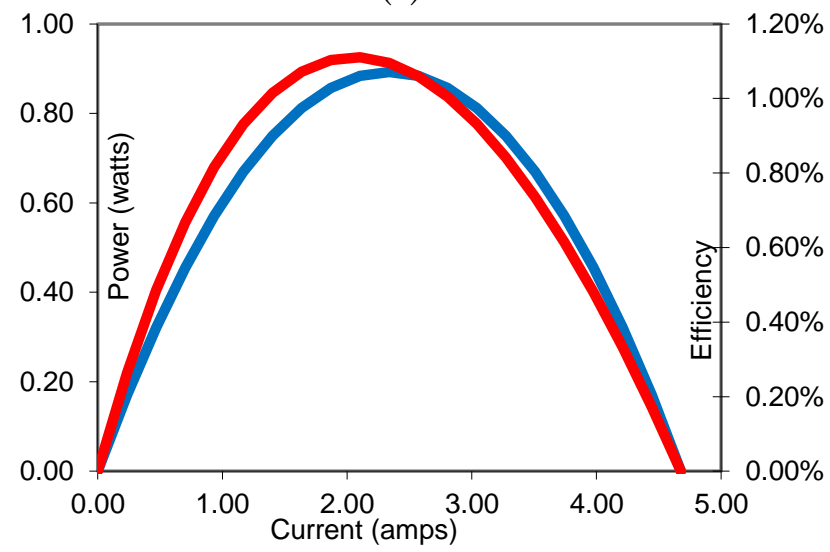

(c)

Fig. 7. HZ-20 Manufacturer characteristics datasheet for the power outputs (blue) and efficiencies (red) with respect to electric current in the cases of (a) $\Delta \mathrm{T}=17$, (b) $\Delta \mathrm{T}=27$ and (c) $\Delta \mathrm{T}=37$.

Theoretical results of the maximum power output and corresponding conversion efficiency of TEG are shown in Fig. 9a and 9b for different hot fluid temperatures. As can be seen from the Fig. 9, the maximum power output and conversion efficiency increase with increasing hot fluid inlet temperature as well as with decreasing cold fluid inlet temperature. 


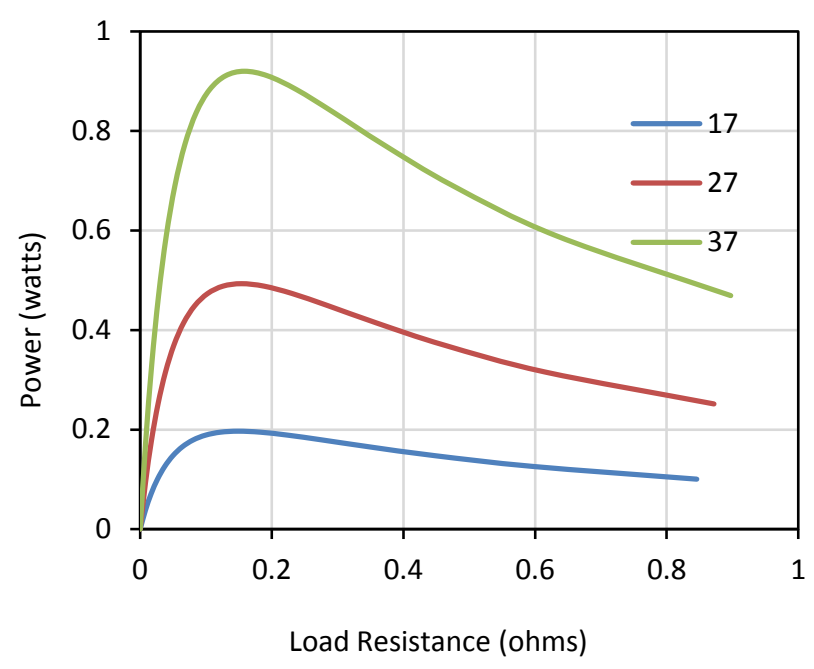

Fig. 8. HZ-20 Manufacturer characteristics datasheet for the power outputs with the load resistance in the cases of $\Delta \mathrm{T}=17$, $\Delta \mathrm{T}=27$ and $\Delta \mathrm{T}=37^{\circ} \mathrm{C}$.

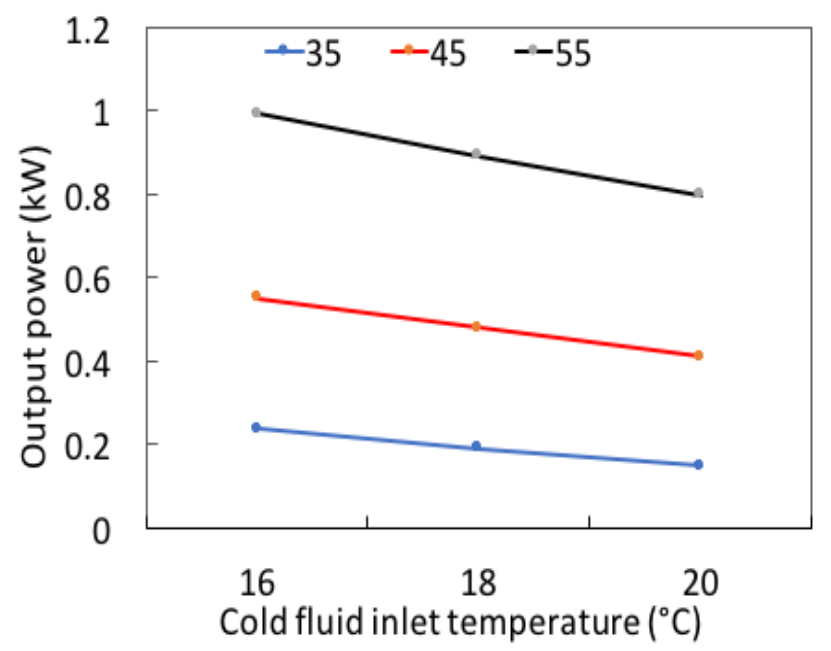

(a)

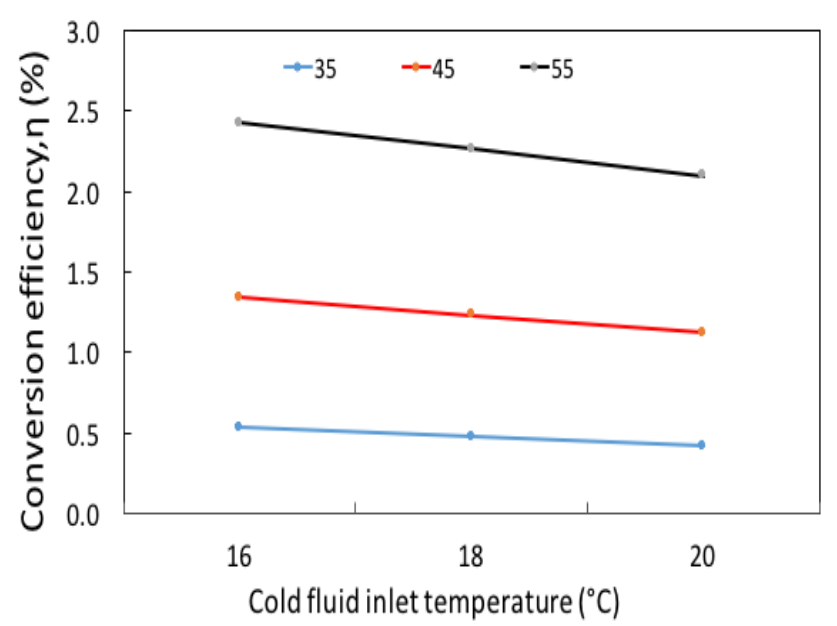

(b)

Fig. 9. (a) Maximum power output and (b) conversion efficiency as a function of different hot fluid temperatures.

\section{Conclusions}

A TEG device is considered to be installed into the exhaust unit of a VVER-1000 NPP condenser in order to recover the waste heat. In this study, a theoretic model of TEG unit has been designed, calculated for low-temperature waste heat power recovery. The results derived from the theoretical data. This system model performance can be assessed by the theoretic analysis results. The results show that both the maximum power output and the corresponding conversion efficiency are greatly affected by the operating conditions, especially the hot fluid inlet temperature. It can be seen that the power output and conversion efficiency increase with increasing the temperature difference.

If all the assessing condensed water is installed with a TEG, the total power generation is found around 35.105 MW for $\Delta \mathrm{T}=17 ; 55.918 \mathrm{MW}$ for $\Delta \mathrm{T}=$ 27 and $76.956 \mathrm{MW}$ for $\Delta \mathrm{T}=37$ can be generated. It was calculated that by using the designed TE generator, about $76.956 \mathrm{MW}$ of the wasted heat in the 1000 MW nuclear power plant could be converted to electricity. The designing increased the electricity generation efficiency for about 2,0\%. By means of the theoretic analysis, it has been found that besides increasing waste heat temperature and TE modules in series, one can enhance the use of waste heat capacity from VVER-1000 NPP and that co-generation method can be a safe method to enhance the performance of the NPPs. The results of theoretical analysis show that TEG has a promising potential at the recovery of waste heat for even low temperatures in especially nuclear and industrial areas. The TEGs would be to have a useful power source that can be safely and easily attached to condenser unit within nuclear plants to generate electricity from waste heat energy. Large quantities of unused heat are wasted in the environment when a reactor turns heat into electricity. For a better energy management, it seems to be technically possible to recover some of this heat. In the future, thermal and nuclear cogeneration will naturally assume increasingly important role.

\section{Acknowledgements}

The authors are grateful to EU Ministry of Turkey National Agency under Grant No: 2015-1-TR01KA203-021342 (Innovative European Studies on Renewable Energy Systems) for the support of that research.

\section{References}

Bianchini, A., Pellegrini, M. and Saccani, C. (2014). Thermoelectric Cells Cogeneration from Biomass Power Plant. Energy Procedia 45, $268-277$.

Gabbar, H.A., Stoute, C.A.B., Steele, D., Simkin, C., Sleeman, T., Newell, D., Paterson, D., Boafo, E. (2017).Evaluation and 
optimization of thermoelectric generator network for waste heat utilization in nuclear power plants and non-nuclear energy applications. Annals of Nuclear Energy, 101, 454464.

Gou, X., Xiau, H. and Yang, S. (2010). Modeling, Experimental Study and Optimization on Low temperature Waste Heat Thermoelectric Generator System. Applied Energy, 87(10), 3131-3136.

Hendricks, T. and Choate, W.,T. (2006). Engineering Scoping Study of Thermoelectric Generator Systems for Industrial Waste Heat Recovery, Pacific Northwest National Laboratory, BCS, Incorporated, November 2006.

http://hi-z.com/wp-content/uploads/2017/05/Data-Sheet-HZ20.pdf

http://www.thermoelectrics.caltech.edu/thermoelectrics/index.ht $\mathrm{ml}$

Ismail, B.I. and Ahmed, W.H. (2009). Thermoelectric Power Generation using Waste-Heat Energy as an Alternative Green Technology. Recent Patents on Electrical Engineering, 2, 27- 39.

Khamis, I., Koshy, T. and Kavvadias, K.C. (2013). Opportunity for Cogeneration in Nuclear Power Plants" Advances in Nano, Biomechanics, Robotics and Energy Research (ANBRE13), Seoul, Korea, August 25-28, 2013.
Kyono, T., Suzuki, R.,O. and Ono, K. (2003). Conversion of Unused Heat Energy to Electricity by Means of Thermoelectric Generation in Condenser. IEEE Transactions On Energy Conversion, 18(2), 330-334.

Riffat, S.B. and Ma, X. (2003). Thermoelectrics: a Review of Present and Potential Applications. Applied Thermal Engineering, 23(8), 913-935.

Rowe D. M, Min, G. (1996). Evaluation of Thermoelectric Modules for Power Generation. J Power Sources, 73,193-8.

Rowe, D.M., (2006). Thermoelectric Waste Heat Recovery as a Renewable Energy Source. International Journal of Innovations in Energy Systems and Power, 1(1), 13-23.

Terzi, R., Tükenmez, I. and Kurt, E. (2016). Energy and Exergy Analyses of a VVER Nuclear Power Plant. International Journal of Hydrogen Energy, 41, 1-12, 2016.

Tsai, H.L. and Lin, J.M. (2009). Model Building and Simulation of Thermoelectric Module Using Matlab/Simulink". Journal of Electronic Materials, 39(9), 2105-2111.

Xi, H., Luo, L. and Fraisse, G. (2007). Development and Applications of Solar-based Thermoelectric Technologies". Renewable and Sustainable Energy Reviews, 11(5), 923-936. 